HEAD AND NECK

\title{
Functional outcomes of supraglottic squamous cell carcinoma treated by transoral laser microsurgery compared with horizontal supraglottic laryngectomy in patients younger and older than 65 years
}

\author{
Risultati funzionali in pazienti over e under 65 affetti da carcinoma squamocellulare \\ sopraglottico trattati con chirurgia laser trans-orale o tradizionale laringectomia \\ orizzontale sopraglottica
}

\author{
C.M CHIESA ESTOMBA, F.A. BETANCES REINOSO, A.I. LORENZO LORENZO, J.L FARIÑA CONDE, \\ J. ARAUJO NORES, C. SANTIDRIAN HIDALGO \\ Otorhinolaryngology, Head \& Neck Surgery Department, University Hospital of Vigo, Spain
}

\section{SUMMARY}

The treatment of supraglottic carcinoma remains a controversial issue. Five accepted surgical and non-surgical oncological treatments have been currently established: standard horizontal supraglottic laryngectomy (HSL), supraglottic CO2 laser microsurgery (TLM), transoral robotic surgery, radiotherapy alone and radiotherapy in combination with chemotherapy. Some studies have shown that complications of head and neck surgeries increase significantly in patients over 65 years compared to younger patients. We designed a retrospective analysis to assess the rate of complications and functional outcomes of patients treated by TLM and HSL in cases of T1-T3 supraglottic squamous cell carcinomas (SCC) in a tertiary University Hospital. Results were compared between patients younger and older than 65 years. We found significant differences in the rate of aspiration pneumonia $(\mathrm{p}=0.026)$, mean time to decannulation $(\mathrm{p}=0.001)$ and mean hospital stay $(p=0.007)$ in patients treated by TLM, which was higher and longer in the group of patients over 65 years of age. Regarding HPL, we only found significant differences in the mean time to decannulation $(p=0.001)$, which was longer in the group of patients younger than 65 years. According to our results, TLM or HPL can both be a safe surgical option for patients older than 65 years, but previous evaluation of lung function before surgery is mandatory because of an increased risk of aspiration pneumonia in patients with lung problems, especially when treated by TLM. Concerning functional outcomes in patients older than 65 years, TLM reduces the postoperative rate of tracheostomy, mean time required for decannulation and mean hospital stay compared with HPL. However, no significant difference in the occurrence of aspiration pneumonia, dysphagia or in the mean length of NGT feeding was found.

KEY WORDS: Squamous cell carcinoma $\bullet$ Supraglottis $\bullet$ Complications $\bullet$ Laser CO2

\section{RIASSUNTO}

Il trattamento dei carcinomi sopraglottici rappresenta al momento una problematica controversa. Al momento sono disponibili 5 differenti opzioni di trattamento: la tradizionale laringectomia orizzontale sopraglottica (HSL), la laringectomia sopraglottica con laser CO2 (TLM), l'approccio mediante chirurgia robotica, la radioterapia e la radioterapia in combinazione con la radiochemioterapia. Alcuni studi hanno evidenziato come il rate di complicanze della chirurgia del distretto testa collo aumenti significativamente nei soggetti al di sopra dei 65 anni. Abbiamo pertanto voluto effettuare uno studio retrospettivo che confrontasse i risultati funzionali e il rate di complicanze nei pazienti al di sotto e al di sopra dei 65 anni, affetti da carcinomi squamocellulari sopraglottici T1-T3, sottoposti a laringectomia orizzontale sopraglottica tradizionale (HSL) o a TLM presso un Polo ospedaliero Universitario di terzo livello. Il gruppo di pazienti al di sopra dei 65 anni sottoposto a TLM ha mostrato differenze statisticamente significative per quanto riguarda il rate di polmonite ab ingestis $(p=0.026)$, tempo medio necessario al decannulamento $(p=0.001)$ e tempo medio di ricovero ospedaliero $(p=0.007)$ tutti risultati più lunghi rispetto a quelli osservati nei pazienti al di sotto dei 65 anni. Per quanto riguarda la chirurgia open, abbiamo rilevato una differenza statisticamente significativa solo per il tempo medio necessario per il decannulamento $(p=0.001)$ risultato essere più lungo nel gruppo di pazienti più giovani di 65 anni. In accordo coi nostri risultati sia la TLM che l'approccio open rappresentano opzioni sicure nei pazienti al di sopra dei 65 anni, ma in cosiderazione dell'aumentato rischio di polmonite ab ingestis è mandatoria un adeguata valutazione della funzionalità polmonare preoperatoria, in particolare nei pazienti trattati con TLM. Nei pazienti al di sopra dei 65 anni inoltre la TLM rispetto all'approccio open riduce il rate di tracheostomie postoperatorie, il tempo medio necessario al decannulamento e il tempo medio di ricovero. Tuttavia non è stata rilevata alcuna differenza significativa in termini di rate di polmonite ab ingestis, disfagia o tempo medio di utilizzo del sondino naso gastrico. 


\section{Introduction}

Laryngeal tumours represent approximately $2 \%$ of all tumours and are the second most common tumour in the head and neck region ${ }^{1}$. Approximately one-third affect the supraglottic region and $90 \%$ are histopathologically squamous cell carcinomas ${ }^{2}$.

The treatment of supraglottic carcinoma is still a controversial issue. Many accepted surgical and non-surgical oncological treatments have been currently established. In locally advanced laryngeal carcinomas, total laryngectomy has been the mainstay of treatment for decades ${ }^{3}$, but horizontal supraglottic laryngectomy ${ }^{4}$ (HSL) and more recently supracricoid laryngectomy, supratracheal laryngectomy, supraglottic CO2 laser microsurgery (TLM) ${ }^{5-9}$, transoral robotic surgery (TORS), radiotherapy alone or radiotherapy in combination with chemotherapy are accepted options. These options can be used together or separately. For example, in the case of early or well selected advanced supraglottic carcinoma, this can be treated successfully with HSL, TLM or radiotherapy ${ }^{10}$, but robotic surgery is also an option. The addition to radiotherapy and chemotherapy is also generating interest. Key principles must be taken into account to determine patient eligibility for an organ preservation or surgical approach, because even though local control is the main goal of the treatment, the preservation of laryngeal function must be effective to achieve consistent functional outcomes in terms of speech and swallowing. Furthermore, the eligibility of the patients is based on the extent of tumour and not only on the T classification ${ }^{11-13}$.

In reality, the proportion of deaths due to cancer has been increasing among elderly people, and this is frequent in developing countries. Patients over 65 years with laryngeal carcinoma have their own particular characteristics. Age is considered a major risk factor for development of laryngeal tumours, although symptoms of cancer are less evident in elderly patients, due to sensory hypofunction and frequent confusion of cancer symptoms with the symptoms of various pre-existing diseases. These factors may result in misdiagnosis or delayed diagnosis ${ }^{14}$. The risk of the surgery also increases in elderly patients due to frequent age-related chronic systemic diseases ${ }^{15}$.

Some studies have shown that complications of head and neck surgeries are increased significantly in elderly patients ${ }^{16}$. Due to the high rate of complications related to the treatment of these tumours in patients over 65 years of age, surgical treatment is not widely accepted. However, only few studies have compared the rate of complications related to the treatment of supraglottic squamous cell carcinoma between TLM or HSL in elderly patients.

For this reason, the aim of this study was to retrospectively evaluate the rate of complications and oncological and functional outcomes obtained in a series of elderly patients treated by TLM and HPL for cT1-cT3 supraglottic squamous cell carcinomas (SCC) in a tertiary University Hospital and compared with a control group of younger patients.

\section{Materials and methods}

A retrospective analysis was performed on previously untreated patients diagnosed with squamous cell carcinoma (SCC) of the supraglottis (cT1-cT3), N -/+, M -/+ according to criteria of the Union Internationale Contre le Cancer (UICC) and the American Joint Committee on Cancer (AJCC). Patients were divided in two groups according to age (younger and older than 65 years). All patients treated with curative intent by TLM or HSL between January 2010 and January 2012 were included, and patients who had received prior treatment with another surgical technique or those who had received prior RT were excluded. Identification of cases was achieved by computerised research on the medical records of our database, using the International Classification of Diseases (ICD-9). This study was approved by the ethics committee of our centre. The demographic data (age, sex), past medical history, comorbidities, stage, imaging, complications, outcomes after surgery, type of surgery, etc., were obtained by review of medical history.

\section{Preoperative examination}

Prior to surgery, all cases were discussed in an interdisciplinary committee of head and neck tumours. Preoperative examination of the lesion was carried out by indirect laryngoscopy, videolaryngoscopy and CT or MRI of the neck to evaluate cartilage, preepiglottic and paraglottic space and lymph node involvement. Fine needle biopsies of the neck nodes were normally performed under ultrasonographic control. Patients with lesions suspicious for malignancy were scheduled for laryngeal microsurgery and pan-endoscopy with biopsies, followed by TLM or HSL in cases that were positive for malignancy if they had adequate pulmonary function (pulmonary function tests, such as vital capacity and forced expiratory volume in 1 second, were done in patients with history of chronic obstructive pulmonary disease). After surgery, pTNM classification was presented in the multidisciplinary committee and the need for reoperation or additional radiotherapy (RT) or chemoradiotherapy (QT/RT) was assessed.

\section{Operative technique}

The type of surgery, whether TLM or HSL, was selected according to the clinical tumour stage and difficulty of exposure. TLM was performed on tumours not involving the vocal cords or the laryngeal framework or involving not more than 1 arytenoid. When indicated, supraglottic resection was extended to the valleculae, the base of the tongue and the medial wall of the pyriform fossae. The indication for transoral laser $\mathrm{CO} 2$ surgery was made if 
the tumour was completely exposable during the previous laryngeal microsurgery. If, however, the vocal cords were fixated, the laryngeal framework affected or the base of tongue or hypopharynx was not completely exposable during direct laryngoscopy, an open procedure was indicated.

All patients underwent a general anaesthesia with orotracheal intubation, and resection was performed using a Lumenis CO2 laser device (Yokneam, Israel), with a power setting of 10-12 W, used in superpulsed mode and continuous setting, varying size and shape of the spot according to the moment of the surgery by using the micro-manipulator Acuspot-Acublade (Lumenis). In the case of small tumours, whenever possible, en bloc resection was attempted and the excised piece was pinned and orientated on a corkboard. In larger lesions, a piecemeal resection was often the only option. In all cases surgeons tried to achieve a margin of healthy tissue of 2-3 mm, trying to preserve functions without affecting the oncological radicality of the procedure. During surgery no intraoperative biopsies were performed if the resection was satisfactory. However, when the depth of cancer infiltration was difficult to estimate a frozen section was sent for examination. Subsequently, vaporisation of the surgical site was performed to prevent tumour recurrence when the frozen section was positive ${ }^{18}$. Resection margins were classified as free, uncertain, or affected according to Blanch et al. ${ }^{18}$. In cases of affected margins, re-intervention was performed. Those patients with uncertain margins were followed up and only in the case of finding persistence or recurrence was another surgery was performed.

HSL was indicated in patients regardless of age and stage (cT1-cT3), when resection was not possible by TLM due to the difficulty of exposure of the lesion or the tumour size and when no involvement of the vocal cords or laryngeal framework was seen. Extension to the base of the tongue or the hypopharynx was not considered a contraindication. Preepiglottic o paraglottic space involvement was considering a contraindication to this technique in our centre. However, according with other reports, in selected tumours classified as T3 due to limited paraglottic spread without fixation of the arytenoid cartilage, this surgery can be an option ${ }^{19}$. All the supraglottic laryngectomies included in the study were performed using a modification of the Alonso's technique described by Herranz et al. ${ }^{20}$, (In all external neck approaches we always perform a tracheotomy). The type of surgery (endoscopic supraglottic $\mathrm{CO}_{2}$ laser partial laryngectomy or open partial horizontal laryngectomies) was classified according to the European Laryngological Society (ELS) proposal ${ }^{21} 22$. In all cases, the XII cranial nerve and superior laryngeal nerve were intended to be preserved. Advanced chronic respiratory disease was considered a major contraindication.

\section{Treatment of the neck}

In patients treated by HSL who presented positive neck lymph nodes (N1, N2), a selective neck dissection including levels II, III, IV and V was performed in the same surgical procedure. In those patients treated by TLM, the selective neck dissection was performed in a second procedure 3 weeks after the initial tumour resection, accompanied by second look microlaryngoscopy exploration. Patients classified as N0 were followed up and only if metastatic disease became evident was a functional neck dissection with microlaryngoscopy exploration performed.

\section{Oral intake}

For patients treated by TLM, oral intake was commenced 6 hours after the procedure if the resection was small. In more advanced tumours, we used a nasogastric feeding tube (NGT) and waited 24-48 hours to start oral intake. In patients treated by HPL, a NGT was inserted and no oral intake was allowed for the first week.

\section{Follow-up}

In our department, patients diagnosed and treated for head and neck malignant tumours are followed up for at least 5 years by the Head and Neck Oncology Team. However, for this study we considered a group of patients that has been followed up by a minimum of 36 months ( 3 years).

\section{Complementary treatment}

Additional postoperative radiotherapy was administered to some patients in both groups in advanced neck disease $(\mathrm{N} 2 \mathrm{a} / \mathrm{b} / \mathrm{c})$ when the histopathological examination revealed extracapsular spread or in those patients with lymphatic micrometastases. Patients with histologically close surgical margins, mainly at the base of the tongue, also received post-surgical radiotherapy for 4 weeks postoperatively followed by weekly doses to reach a total dose of $60 \mathrm{~Gy}$.

\section{Statistical analysis}

Statistical analysis was run by the SPSS program for Windows, Version 20.0 (SPSS, Inc. Illinois, USA). Quantitative variables in the study are expressed as mean \pm typical deviation. The different variables were correlated by Pearson's chi-square test and for the comparison of continuous variables (mean hospital stay, mean time to decannulation, aspiration pneumonia, NGT mean duration, tracheostomy duration, need of percutaneous gastrostomy) between both groups of elderly patients the Mann-Whitney $\mathrm{U}$ test was used. $\mathrm{P}$ values of $<0.05$ were considered to be statistically significant in all tests. We calculated overall survival and disease-specific survival using Kaplan-Meier survival analysis. As reference for overall survival, we used the survival time from the surgery until the last revision or date of death regardless of cause. For disease-spe- 
Table I. Type of endoscopic supraglottic $\mathrm{CO}_{2}$ laser partial laryngectomy according to ELS classification.

\begin{tabular}{lcc} 
Type of cordectomy & Number & $\%$ \\
Type Ila & 3 & 9.7 \\
Type Illb & 2 & 6.5 \\
Type Illa & 6 & 19.4 \\
Type IIIb & 4 & 12.9 \\
Type IVa & 5 & 16.1 \\
Type IVb & 11 & 35.5 \\
Total & 31 & 100.0 \\
\hline
\end{tabular}

cific survival, we considered the time between the surgery until death by tumour or until total laryngectomy was performed. We calculated the influence of various factors on survival using the log-rank method.

\section{Results}

47 patients met the inclusion criteria, $44(93.6 \%)$ patients were male and $3(6.4 \%)$ were females. $31(65.9 \%)$ of them were treated with TLM and $16(34.1 \%)$ were treated with HSL. All data are presented in Tables I, II and III for TLM and in Tables IV and V for HSL.

Other factors are shown in Tables II to VI such as: classification according to the type of endoscopic $\mathrm{CO}_{2}$ laser supraglottic laryngectomy in the group of patients treated by TLM, results of both groups according to TNM classification, mean hospital stay, mean time to decannulation, post-surgical complications including postoperative bleeding, urgent tracheotomy, number of patients who required NGT or percutaneous gastrostomy tube (PEG), postoperative dysphagia and complications associated with the surgical technique such as aspiration pneumonia and chondritis of the thyroid cartilage.

In the group of patients treated by TLM, we found statistically significant differences between both groups of patients with regards to the presence of comorbidities, specifically in the group of patients over 65 years where diabetes $(p=0.017)$ was found to be more frequent. In terms of post-surgical complications, we found a significant difference in the incidence of aspiration pneumonia which was also higher in the group of patients over 65 years $(p=0.026)$. We also found a difference in the mean time to decannulation $(\mathrm{p}=0.001)$ and average hospital stay $(\mathrm{p}=0.007)$, which were both longer in the group of patients over 65 years (Tables II, III).

No correlation was found between the need for tracheostomy in patients treated by TLM and T stage $(\mathrm{p}=0.862)$. In all patients treated by TLM, we analysed the possible effect of radiotherapy $(<65=10 / 14 ;>65=7 / 17$ : $\mathrm{p}=0.160)$ or cervical neck dissection $(\mathrm{p}=0.316)$ on the rate of aspiration pneumonia and there was no statistical correlation. Furthermore, we examined the possible effect of arytenoid resection on the rate of dysphagia $(\mathrm{p}=0.507)$ and there was no relation.

In the group of patients treated with HSL, we did not find significant differences between the two groups of patients with regards to the presence of comorbidities or post-surgical complications. We found significant differences in the mean

Table II. Demographic and oncologic data of patients treated with TLM divided according to age.

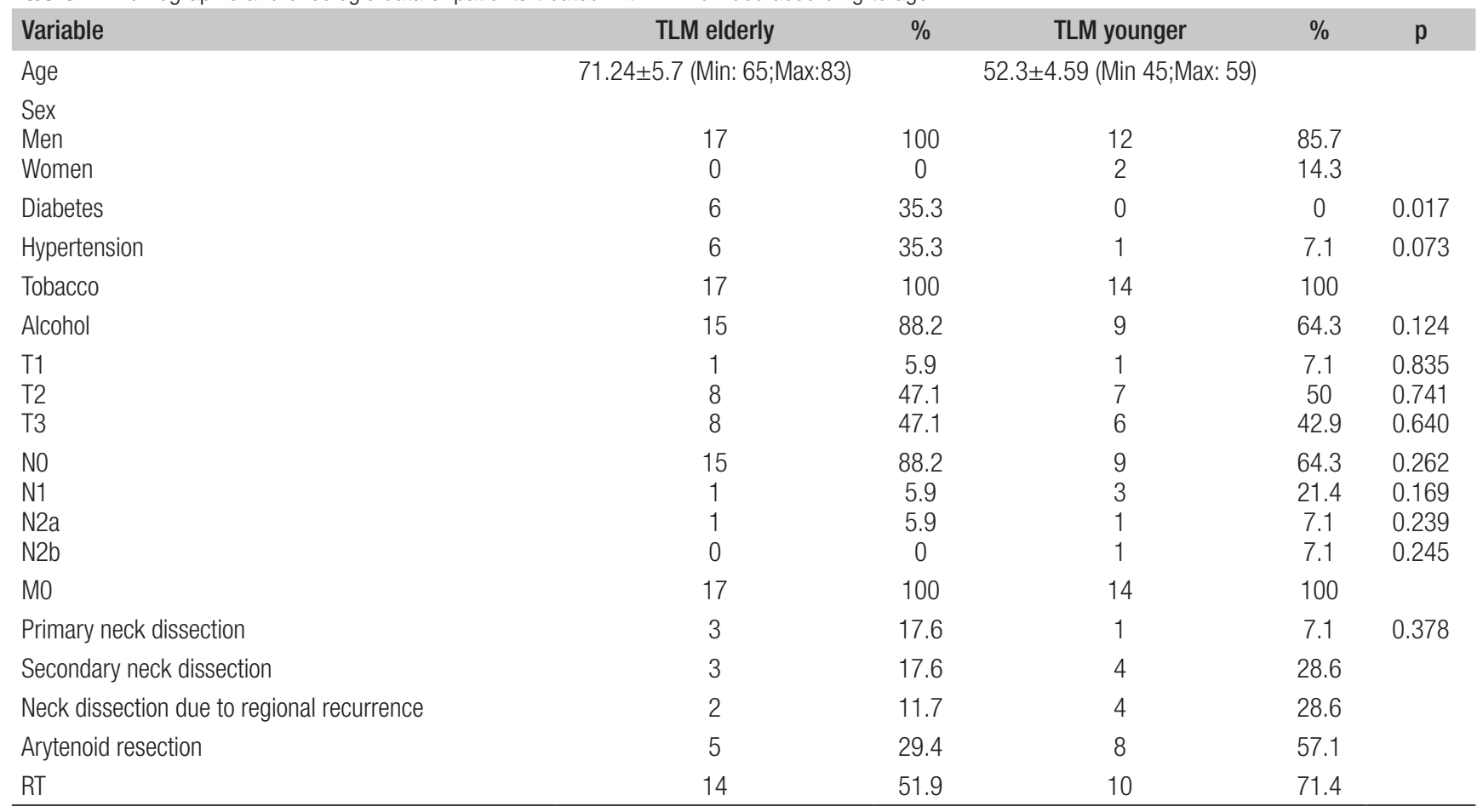


Table III. Complications and clinical outcomes of both groups of patients treated with TLM divided according to age.

\begin{tabular}{|c|c|c|c|c|c|}
\hline Variable & TLM elderly & $\%$ & TLM younger & $\%$ & $\mathrm{p}$ \\
\hline $\begin{array}{l}\text { Post-Surgical bleeding } \\
\text { (Primary procedure) }\end{array}$ & 3 & 17.6 & 1 & 7.1 & 0.378 \\
\hline Tracheostomy & 4 & 23.5 & 1 & 7.1 & 0.233 \\
\hline Cervical abscess (Neck dissection) & 1 & 5.9 & 1 & 7.1 & 0.708 \\
\hline Chondritis & 1 & 5.9 & 0 & 0 & 0.548 \\
\hline Aspiration pneumonia & 7 & 41.2 & 0 & 0 & 0.026 \\
\hline Laryngeal stenosis & 0 & 0 & 2 & 14.3 & 0.406 \\
\hline NGT & 15 & 88.2 & 10 & 71.4 & 0.235 \\
\hline NGT mean duration & $\begin{array}{c}7.53 \pm 6.79 \\
(\text { Min:2/Max:27) }\end{array}$ & & $\begin{array}{c}3.64 \pm 2.84 \\
\text { (Min:1/Max:9) }\end{array}$ & & 0.080 \\
\hline PEG & 4 & 23.5 & 0 & 0 & 0.076 \\
\hline Dysphagia & 5 & 29.4 & 5 & 35.7 & 0.590 \\
\hline Failed decannulation & 2 & 11.8 & 0 & & 0.406 \\
\hline Mean time to decanulation & $\begin{array}{l}45.8 \pm 132 \text { Days } \\
\text { (Min:30/Max:540) }\end{array}$ & & $\begin{array}{c}\text { 14Days } \\
\text { (Only } 1 \text { patient needs a traqueostomy) }\end{array}$ & & 0.001 \\
\hline Mean hospital stay & $\begin{array}{c}17.41 \pm 34.3 \\
\text { (Min:2/Max:149) }\end{array}$ & & $\begin{array}{c}8.21 \pm 3.55 \\
\text { (Min:4/Max:15) }\end{array}$ & & 0.007 \\
\hline
\end{tabular}

Table IV. Demographic and oncologic data of patients treated with HSL divided according to age.

\begin{tabular}{|c|c|c|c|c|c|}
\hline Variable & HSL elderly & $\%$ & HSL younger & $\%$ & $p$ \\
\hline Age & $\begin{array}{c}66.6 \pm 2.41 \\
\text { (Min: 65/Max: 71) }\end{array}$ & & $\begin{array}{c}49.50 \pm 3.1 \\
\text { (Min: 44/Max: 53) }\end{array}$ & & \\
\hline $\begin{array}{l}\text { Sex } \\
\text { Men } \\
\text { Women }\end{array}$ & $\begin{array}{c}10 \\
0\end{array}$ & $\begin{array}{c}100 \\
0\end{array}$ & $\begin{array}{l}5 \\
1\end{array}$ & $\begin{array}{l}83.3 \\
16.7\end{array}$ & \\
\hline Diabetes & 1 & 10 & 0 & 0 & 0.563 \\
\hline Hypertension & 4 & 40 & 1 & 16.7 & 0.231 \\
\hline Tobacco & 10 & 100 & 6 & 100 & \\
\hline Alcohol & 10 & 100 & 5 & 83.3 & 0.468 \\
\hline $\begin{array}{l}\text { T1 } \\
\text { T2 } \\
\text { T3 }\end{array}$ & $\begin{array}{l}0 \\
6 \\
4\end{array}$ & $\begin{array}{c}0 \\
60 \\
40\end{array}$ & $\begin{array}{l}1 \\
3 \\
2\end{array}$ & $\begin{array}{c}16.7 \\
50 \\
33.3\end{array}$ & $\begin{array}{l}0.460 \\
0.382 \\
0.320\end{array}$ \\
\hline $\begin{array}{l}\text { N0 } \\
\text { N1 } \\
\text { N2a } \\
\text { N2b } \\
\text { N2C }\end{array}$ & $\begin{array}{l}5 \\
3 \\
0 \\
1 \\
1\end{array}$ & $\begin{array}{c}50 \\
30 \\
0 \\
10 \\
10\end{array}$ & $\begin{array}{l}1 \\
2 \\
2 \\
1 \\
0\end{array}$ & $\begin{array}{c}16.7 \\
33.3 \\
33.3 \\
16.7 \\
0\end{array}$ & $\begin{array}{l}0.102 \\
0.382 \\
0.320 \\
0.372 \\
0.563\end{array}$ \\
\hline M0 & 10 & 100 & 6 & 100 & 0 \\
\hline Primary neck dissection & 10 & 100 & 6 & 100 & 0.617 \\
\hline Secondary neck dissection & 0 & 0 & 0 & 0 & \\
\hline Arytenoid resection & 4 & 40 & 2 & 33.3 & \\
\hline RT & 4 & 40 & 4 & 66.6 & \\
\hline
\end{tabular}

time to decannulation $(p=0.001)$, which was longer in the group of patients younger than 65 years (Tables IV, V).

In all patients treated by HSL, we also analysed the influence of post-operative radiotherapy $(<65=4 / 6$ : $p=0.368 />65=4 / 10: p=0.667)$ or cervical neck dissection $(p=0.337)$ in patients on the rate of aspiration pneumonia and possible effect of arytenoid resection on the rate of dysphagia $(\mathrm{p}=0.451)$ and again no statistical correlation was found.
When comparing the two groups of patients over 65 years treated by either TLM or HSL, we found significant differences in the need for tracheostomy $(p=0.001)$, mean time required for decannulation $(p=0.001)$ and mean hospital stay $(p=0.003)$, all in favour of TLM. However, no significant difference was found in the incidence of aspiration pneumonia $(\mathrm{p}=0.343)$, dysphagia $(\mathrm{p}=0.117)$ or in the average length of NFT $(p=0.700)$ (Table VIII). Finally, in the group of patients treated by TLM a total of 
Table V. Complications and clinical outcomes of both groups of patients treated with HSL divided according to age.

\begin{tabular}{|c|c|c|c|c|c|}
\hline Variable & HSL elderly & $\%$ & HSL younger & $\%$ & $\mathrm{p}$ \\
\hline $\begin{array}{l}\text { Post-Surgical bleeding } \\
\text { (Primary procedure) }\end{array}$ & 0 & 0 & 1 & 16.7 & 0.438 \\
\hline Tracheostomy & 10 & 100 & 6 & 100 & \\
\hline Cervical abscess (Neck dissection) & 0 & 0 & 1 & 16.7 & 0.438 \\
\hline Chondritis & 0 & 0 & 0 & 0 & 0 \\
\hline Aspiration pneumonia & 2 & 20 & 1 & 16.7 & 0.400 \\
\hline Laryngeal stenosis & 0 & 0 & 0 & 0 & 0 \\
\hline Cervical fistula & 1 & 10 & 1 & 16.7 & 0.230 \\
\hline NGT & 10 & 100 & 6 & 100 & \\
\hline NGT mean duration & $\begin{array}{c}11.80 \pm 9.5 \\
\text { (Min: 6/Max: 38) }\end{array}$ & & $\begin{array}{c}8.50 \pm 4.5 \\
\text { (Min: 4/Max: 15). }\end{array}$ & & 0.248 \\
\hline PEG & 2 & 20 & 1 & 16.7 & 0.600 \\
\hline Dysphagia & 3 & 30 & 4 & 66.7 & 0.329 \\
\hline Failed decannulation & 5 & 50 & 3 & 50 & \\
\hline Mean time to decanulation & $\begin{array}{c}160.4 \pm 126.5 \\
\text { (Min: 31/Max: 407) }\end{array}$ & & $\begin{array}{l}233.67 \pm 169.66 \\
\text { (Min: 32/Max: 501) }\end{array}$ & & 0.001 \\
\hline Mean hospital stay & $\begin{array}{c}20.50 \pm 7.69 \\
\text { (Min: 14/Max: 39) }\end{array}$ & & $\begin{array}{c}21.67 \pm 10.1 \\
\text { (Min: } 12 / \text { Max: 40) }\end{array}$ & & 0.451 \\
\hline
\end{tabular}

Table VI. Comparision of continuous variables between both groups in elderly patients.

\begin{tabular}{|c|c|c|c|c|c|}
\hline Variable & HSL elderly & $\%$ & TLM elderly & $\%$ & $\mathrm{p}$ \\
\hline Mean hospital stay & $20.50 \pm 7.69$ (Min: 14/Max: 39) & & $17.41 \pm 34.3$ (Min:2/Max:149) & & 0.003 \\
\hline Need for tracheostomy & 10 & 100 & 4 & 23.5 & 0.001 \\
\hline Mean time to decanulation & $\begin{array}{c}160.4 \pm 126.5 \text { (Min: 31/Max: } \\
407)\end{array}$ & & $45.8 \pm 132$ Days (Min:30/Max:540) & & 0.001 \\
\hline Aspiration pneumonia & 2 & 20 & 7 & 41.2 & 0.343 \\
\hline Dysphagia & 3 & 30 & 5 & 29.4 & 0.117 \\
\hline NGT mean duration & $11.80 \pm 9.5$ (Min: 6/Max: 38) & & $7.53 \pm 6.79($ Min:2/Max:27) & & 0.700 \\
\hline
\end{tabular}

9 patients $(29 \%)$ needed total laryngectomy, 7 of whom $(22.5 \%)$ due to functional reasons, 4 were from the group of patients over 65 years and 3 from the group of patients younger than 65 years $(\mathrm{p}=0.637)$. On the other hand, in the group of patients treated by HSL, none needed total laryngectomy.

In the group of patients treated by TLM, three year overall survival was $67.7 \%$, while the three year disease-specific survival was $83.8 \%$. In the group of patients treated by HSL, the three year overall survival was $62.5 \%$, and the three year disease-specific survival was $75 \%$. There were no significant differences between both techniques according to overall $(p=0.626)$ or specific survival rates $(\mathrm{p}=0.723)$ (Figs. 1, 2).

Recurrence in the neck was observed in 6 patients treated with TLM, all whom were previously classified as cN0. Those patients were treated with cervical neck dissection. Three patients died from regional recurrence, another due to pneumonia, while 2 patients were alive and diseasefree at the last follow-up.

\section{Discussion}

In general, functional results of TLM are considered by many authors superior to those obtained by HSL. TLM usually shows less time required to restore the patient's swallowing capacity, shorter hospital stay, less need of tracheotomy, lower incidence of aspiration pneumonia and lower incidence of pharyngocutaneous fistulas ${ }^{23-28}$. In contrast, other authors such as Cabanilla et al. ${ }^{29} \mathrm{did}$ not consider these differences as significant. In particular, they compared the rate of functional problems after conventional HSL and reported no significant differences, concluding that the lower rate of patients needing temporary tracheotomy is frequently the major advantage of TLM over HSL. In terms of restoring swallowing capacity, they found faster improvement in tumours endoscopically resected by TLM, but long-term results seemed to be similar in both approaches ${ }^{30}$. Usually these functional advantages can be attributed to the more conservative nature of an endoscopic procedure, because healthy tissue is not 


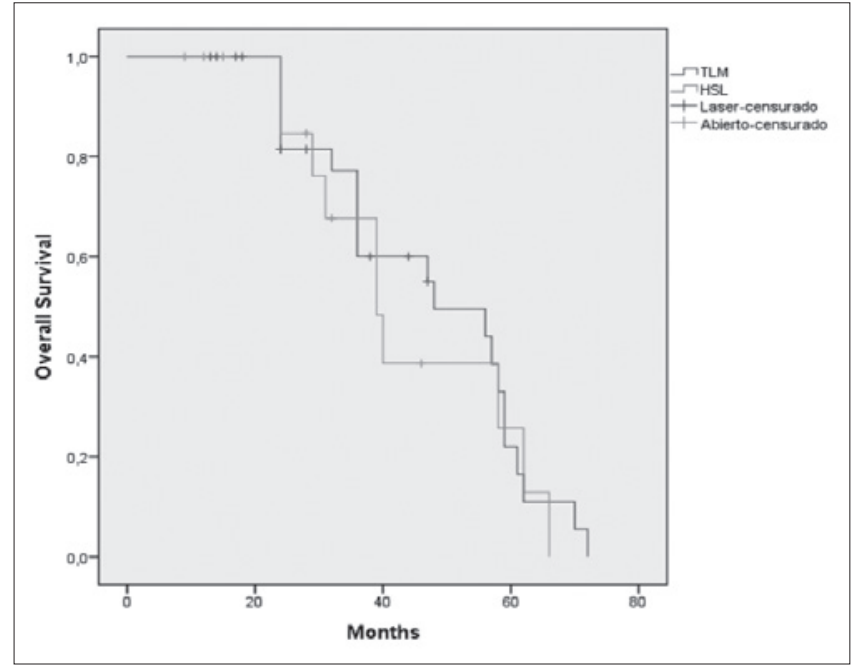

Fig. 1. Kaplan-Meier three-year overall survival according to surgical approach TLM vs. HSL.

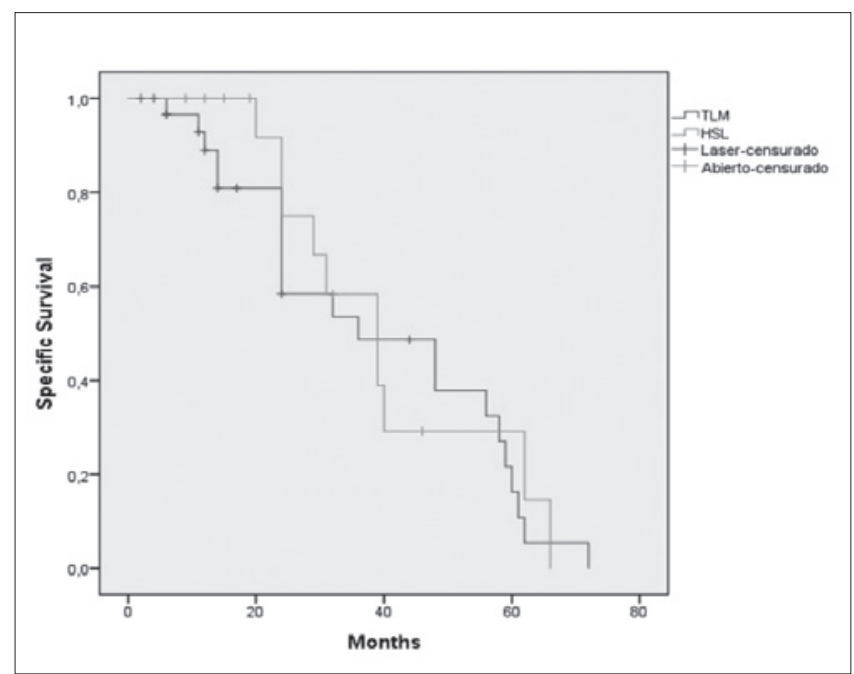

Fig. 2. Kaplan-Meier three-year specific survival according to surgical approach TLM vs. HSL.

involved during the approach. During open procedures, the skin as well as the thyroid cartilage and the soft tissues are involved. The incision and posterior suturing of these structures will almost always result in airway swelling and the need for tracheotomy. This can be avoided in many endoscopic resections ${ }^{29}$.

Regarding the incidence of aspiration pneumonia, different results have been reported in the literature. Köllisch $e t$ $a l$. found an incidence of aspiration pneumonia of $11.5 \%$ ( 3 of 26) in the TLM group compared to $40 \%$ (8 of 20) in the HSL group ${ }^{30}$. On the other hand, Cabanillas et al., found no significant differences in the incidence of aspiration pneumonia (11.5\%) between groups (TLM vs HSL), but did find a correlation between the mean age of patients that was significantly higher in those who suffered aspiration pneumonia ${ }^{29}$. In our study, we only found a signifi- cant difference in the incidence of aspiration pneumonia when comparing both age groups within the group of patient treated with TLM which was higher in the group over 65 years $(p=0.026)$, but when comparing both techniques in the groups of patients over 65 years there were no significant difference.

With regards to mean hospital stay, Cabanilla et al. found no differences in the number of days of postsurgical stay between the two surgical approaches. They hypothesised that the shorter hospital stay after transoral resection is compensated by the stay after neck dissection. In another study, Peretti et al. found a better cost-effectiveness ratio for TLM, since it reduced hospital stay by more than $50 \%$ compared with open neck supraglottic laryngectomies. In our study, we found a significant difference in mean hospital stay $(p=0.007)$ when comparing age groups in patients treated by TLM, resulting in a longer stay in patients over 65 years. According to the type of technique (TLM vs. HSL) in patients over 65 years old, we also found a statistical difference in mean hospital stay $(\mathrm{p}=0.003)$, which was longer in patients treated by HSL.

Regarding the need for tracheostomy, we found no differences between younger and elderly patients in either groups when we compared within the same surgical technique, but we found a significant difference in the need for tracheostomy and mean time to decannulation when we compared the same parameters in patients over 65 years treated with different techniques. Patients over 65 years treated by TLM were found to require fewer tracheostomies and had a shorter time to decannulation (Tab. VII). Others authors ${ }^{32-35}$ who compared the results of TLM and HSL such as Cabanilla et al. found that the avoidance of tracheostomy was the main functional advantage of TLM, but with no difference in the need for a permanent tracheostomy ${ }^{29}$. Peretti et al.performed tracheotomy in only $14 \%$ of patients treated by TLM ${ }^{31}$.

Regarding the presence of swallowing alterations, we found no differences between either of the techniques or age groups. Most authors have suggested that there is better recovery of swallowing after TLM. These outcomes could be due to the less invasive nature of laser surgery, where the muscular structures involved in swallowing are usually respected, whereas open surgery involves damage to the strap muscles and modification of anatomical structures, and therefore alteration of swallowing mechanics. Other parameters like $\mathrm{T}$ classification or psychological motivation have also been correlated to outcomes on swallowing after surgery ${ }^{29}$. This is why the role of postoperative swallowing rehabilitation is so important after these surgeries ${ }^{31}$. Another important issue is the presence of radiotherapy toxicity after HSL treatment. Some authors concluded that radiotherapy influences the swallowing function without affecting the phonatory results ${ }^{36}$. Moreover, Ruberto et al. recently analysed the rate of pexy line rupture in a group of patients treated by par- 
tial laryngectomy, and concluded that it is an infrequent complication that may occur in patients with normal postoperative course after partial laryngectomies, further reporting the appearance of symptoms from the beginning of swallowing exercises. Therefore, is very important to follow the patient closely during the postoperative period, because early diagnosis of a rupture in the pexy can prevent respiratory or infectious complications and massive bleedings ${ }^{18}$.

We found no statistical correlation between adjuvant therapy or cervical neck dissection and the rate of aspiration pneumonia in either type of surgical procedure. Some authors consider the need for adjuvant radiotherapy, which usually results from histopathological findings on surgical specimens, the strongest support for an endoscopic versus an open approach ${ }^{37}$. However, we are not able to give a strong recommendation based on our results about this topic, and probably the small number of patients in this arm does not provide sufficient statistical power. Despite this, we always try to avoid the use of radiotherapy in patients treated by HSL.

Nowadays, transoral robotic surgery (TORS) appears to be an interesting option for resection of head and neck cancer. This technique was introduced in 2006 and the first supraglottic partial laryngectomy with TORS was described in 2007 by Solares et al. who performed an experimental resection of the supraglottis in a cadaver, a dog model and later in a woman with a supraglottic carcinoma ${ }^{38}$. After that, Weistein et al. treated the first three human patients with supraglottic carcinoma by TORS ${ }^{39}$. Later, other authors have attempted to demonstrate the advantages of this new technique by overcoming the limitations of TLM, namely improved visualisation of the surgical field due to the high definition and three dimensional imaging and improved dexterity, due to more degrees of freedom of movement of the robotic arms, filtration of physiological tremor and greater comfort for the surgeon ${ }^{38}$. Other authors suggest that the robotic technique is considerably more comfortable, less fatiguing for the surgeon than the endoscopic technique and less operative time is required, perhaps due to the previous experience of surgeons with endoscopic techniques ${ }^{40}$. However, this technology is not yet available in all centres.

Our study has a number of limitations. Primarily its retrospective nature and the small sample size can limit the validity of our results, as well as the lack of validated questionnaires done on patients. Another limitation is the subjective assessment of the swallowing improvement and the absence of a voice test after surgery. Prospective studies analysing the functional outcomes of these two different approaches to treat supraglottic squamous cell carcinoma will most likely help to decide which surgical path will be more beneficial for the patient, especially in the case of elderly patients.

\section{Conclusions}

In conclusion, TLM or HSL can both be a safe surgical option for patients older than 65 years, but previous evaluation of lung function before surgery is mandatory because of an increased risk of aspiration pneumonia in patients with lung problems, especially when treated by TLM. Concerning functional outcomes in patients older than 65 years, TLM reduces the postoperative rate of tracheostomy, the mean time required for decannulation and the mean hospital stay compared with HSL. However, no significant difference in the occurrence of aspiration pneumonia, dysphagia, or in the mean length of NGT feeding was found.

\section{References}

1 Maurizi M, Paludetti G, Galli J, et al. Oncological and functional outcome of conservative surgery for primary supraglottic cancer. Eur Arch Otorhinolaryngol 1999;256:283-90.

2 Shah JP, Karnnell LH, Hoffmann HT, et al. Patterns of care for cancer of larynx in the United States. Arch Otolaryngol Head Neck Surg 1997;123:475-83.

3 Bussu F, Paludetti G, Almadori G, et al. Comparison of total laryngectomy with surgical (cricohyoidopexy) and nonsurgical organ-preservation modalities in advanced laryngeal squamous cell carcinomas: a multicenter retrospective analysis. Head Neck 2013;35:554-61.

4 Alonso JM. Conservative surgery of cancers of the larynx. Trans Am Acad Ophtalmol Otolaryngol 1947;51:633-42.

5 Strong MS, Jako GJ. Laser surgery in the larynx. Early clinical experience with continuous CO 2 laser. Ann Otol Rhinol Laryngol 1972;81:791-8.

6 Strong MS. Laser excision of carcinoma of the larynx. Laryngoscope 1975;85:1286-9.

7 Vaughan CW. Transoral laryngeal surgery using the CO2 laser: laboratory experiments and clinical experience. Laryngoscope 1978;88:1399-420.

8 Leone CA, Capasso P, Russo G, et al. Supracricoid laryngectomies: oncological and functional results for 152 patients. Acta Otorhinolaryngol Ital 2014;34:317-26.

9 Succo G, Bussi M, Presutti L, et al. Supratracheal laryngectomy: current indications and contraindications. Acta Otorhinolaryngol Ital 2015;35:146-56.

10 Hinerman RW, Mendenhall WM, Amdur RJ, et al. Carcinoma of the supraglottic larynx: treatment results with radiotherapy alone or with planned neck dissection. Head Neck 2002;24:456-67.

11 Sevilla MA, Rodrigo JP, Llorente JL, et al. Supraglottic laryngectomy: analysis of 267 cases. Eur Arch Otorhinolaryngol 2008;265:11-6.

12 Tufano RP. Organ preservation surgery for laryngeal cancer. Otolaryngol Clin North Am 2002;35:1067-80.

13 Prades JM, Simon PG, Timoshenko AP, et al. Extended and standard supraglottic laryngectomies: a review of $110 \mathrm{pa}$ tients. Eur Arch Otorhinolaryngol 2005;262:947-52.

14 Shi RJ, Xu CZ, Zhang CP, et al. Outcomes of laryngectomy in elderly patients with laryngeal carcinoma. Genet Mol Res 2014;13:1955-63. 
15 Peters TT, van der Laan BF, Plaat BE, et al. The impact of comorbidity on treatment-related side effects in older patients with laryngeal cancer. Oral Oncol 2011;47:56-61.

16 Bhattacharyya N and Fried MP. Benchmarks for mortality, morbidity, and length of stay for head and neck surgical procedures. Arch Otolaryngol Head Neck Surg 2001;127:127-32.

17 Blanch JL, Vilaseca I, Bernal-Sprekelsen M, et al. Prognostic significance of surgical margins in transoral CO2 laser microsurgery for T1-T4 pharyngo-laryngeal cancers. Eur Arch Otorhinolaryngol 2007;264:1045-51.

18 Ruberto M, Alicandri-Ciufelli M, Grammatica A, et al. Partial laryngectomies: when the problem is the pexy. Acta Otorhinolaryngol Ital 2014;34:247-52.

19 Herranz J, Gavilán J, Martinez-Vidal J, et al. Horizontal supraglottic laryngectomy: modifications to Alonso's technique. Oper Tech Otolaryngol Head Neck Surg 1993;4:252-7.

20 Remacle M, Hantzakos A, Eckel H, et al. Endoscopic supraglottic laryngectomy: a proposal for a classification by the working committee on nomenclature, European Laryngological Society. Eur Arch Otorhinolaryngol 2009;266:993-8.

21 Succo G, Peretti G, Piazza C, et al. Open partial horizontal laryngectomies: a proposal for classification by the working committee on nomenclature of the European Laryngological Society. Eur Arch Otorhinolaryngol 2014;271:2489-96.

22 Myers EN, Alvi A. Management of carcinoma of the supraglottic larynx: evolution, current concepts, and future trends. Laryngoscope 1996;106:559-67.

23 Iro H, Waldfahrer F, Altendorf-Hofmann A, et al. Transoral laser surgery of supraglottic cancer: follow-up of $141 \mathrm{pa-}$ tients. Arch Otolaryngol Head Neck Surg 1998;124:1245-50.

24 Rudert HH, Werner JA, Höft S. Transoral carbon dioxide laser resection of supraglottic carcinoma. Ann Otol Rhinol Laryngol 1999;108:819-27.

25 Iro H, Hosemann W. Minimally invasive surgery in otorhinolaryngology. Eur Arch Otorhinolaryngol 1993;250:1-10.

26 Oeken J, Hänsch U, Thiel S, et al. Swallowing function after endoscopic resection of supraglottic carcinoma with the carbon dioxide laser. Eur Arch Otorhinolaryngol 2001;258:250-4.

27 Prgomet D, Bumber Z, Bilic M, et al. Videofluoroscopy of the swallowing act after partial supraglottic laryngectomy by CO2 laser. Eur Arch Otorhinolaryngol 2002;259:399-403.
28 Cabanillas R, Rodrigo JP, Llorente JL, et al. Functional outcomes of transoral laser surgery of supraglottic carcinoma compared with a transcervical approach. Head Neck 2004;26:653-9.

29 Köllisch M, Werner JA, Lippert BM, et al. Functional results following partial supraglottic resection. Adv Otorhinolaryngol 1995;49:237-40.

30 Peretti G, Piazza C, Cattaneo A, et al. Comparison of functional outcomes after endoscopic versus open-neck supraglottic laryngectomies. Ann Otol Rhinol Laryngol 2006;115:827-32.

31 Zeitels SM, Koufman JA, Davis RK, Vaughan CW. Endoscopic treatment of supraglottic and hypopharynx cancer. Laryngoscope 1994;104:71-8.

32 Rudert HH, Werner JA. Endoscopic resections of glottic and supraglottic carcinomas with the CO2 laser. Eur Arch Otorhinolaryngol 1995;252:146-8.

33 Iro H, Waldfahrer F, Altendorf-Hofmann A, et al. Transoral laser surgery of supraglottic cancer: follow-up of 141 patients. Arch Otolaryngol Head Neck Surg 1998;124:1245-50.

${ }^{34}$ Canis M, Martin A, Ihler F, et al. Results of transoral laser microsurgery for supraglottic carcinoma in 277 patients. Eur Arch Otorhinolaryngol 2013;270:2315-26.

35 Alicandri-Ciufelli M, Piccinini A, Grammatica A, et al. Voice and swallowing after partial laryngectomy: factors influencing outcome. Head Neck 2013;35:214-9.

36 Bussu F, Almadori G, De Corso E, et al. Endoscopic horizontal partial laryngectomy by $\mathrm{CO}(2)$ laser in the management of supraglottic squamous cell carcinoma. Head Neck 2009;31:1196-206.

37 Solares CA, Strome M. Transoral robot-assisted CO2 laser supraglottic laryngectomy: experimental and clinical data. Laryngoscope 2007;117:817-20.

38 Weinstein GS, O’Malley BW, Jr, SnyderW, et al. Transoral robotic surgery: supraglottic partial laryngectomy. Ann Otol Rhinol Laryngol 2007;116:19-23.

39 Alon EE, Kasperbauer JL, Olsen KD, et al. Feasibility of transoral robotic-assisted supraglottic laryngectomy. Head Neck 2012;34:225-9.

40 Ansarin M, Zorzi S, Massaro MA, et al. Transoral robotic surgery vs transoral laser microsurgery for resection of supraglottic cancer: a pilot surgery. Int J Med Robot 2014;10:107-12.

Address for correspondence: Carlos Chiesa, Department of Otorhinolaryngology, Head and Neck Surgery. University Hospital of Vigo, rua Pizarro, \#11, 4to D. 36204, Vigo, España. Tel. 0034635793 435. E-mail: chiesaestomba86@gmail.com 